ARQGA / 1071

\title{
THE MAIN INDICATIONS AND TECHNIQUES FOR VASCULAR EXCLUSION OF THE LIVER
}

\author{
Eleazar CHAIB ${ }^{1}$, William Abrão SAAD ${ }^{1}$, Ikurou FUJIMURA ${ }^{2}$, \\ Willian Abrão SAAD Jr. ${ }^{4}$ and Joaquim GAMA-RODRIGUES ${ }^{3}$
}

ABSTRACT - Background - The purpose of vascular clamping during the course of liver resection is to reduce bleeding and subsequent complications. Aim - To show both step-by-step surgical techniques for vascular exclusion of the liver and their indications. Methods - It is described the following techniques: clamping of the hepatic pedicle, "Pringle" maneuver; intermittent clamping of the hepatic pedicle; intermittent vascular exclusion of the liver, without vena cava clamping, and hepatic vascular exclusion with vena cava clamping. Also metabolic and homodynamic consequences as well as the technical failure of the application of each of them are discussed. Conclusions - The choice of technique to use for clamping during hepatectomy depends on the surgeon's judgment. Dogmatic or systematic attitude, is prejudiciable for the patient and liver surgeon must be able to use all kinds of clamping.

HEADINGS - Hepatectomy. Constriction. Liver circulation. Hemostasis, surgical.

\section{INTRODUCTION}

Hepatic pedicle clamping ${ }^{(18)}$ is a widely used technique to decrease blood loss during hepatectomy.

In the 90's hepatectomy, now generalized as the "gold standard" for the radical cure of liver cancer, is associated with low morbidity and mortality. Different types of vascular occlusion during hepatectomy have been used to reduce operative blood loss and postoperative complications.

Portal triad clamping (PTC) (Pringle's maneuver) is the occlusion of the hepatic artery and portal vein (inflow stop), the vena cava and hepatic vein being clamp-free ${ }^{(18)}$. Total hepatic vascular exclusion (HVE) associates portal triad clamping with occlusion of the supra- and infrahepatic inferior vena cava (outflow stop). Other, more selective, clamping procedures have also been described: selective inflow occlusion (intrahepatic clamping), selective outflow occlusion (selective hepatic vein occlusion) ${ }^{(8)}$.

Clamping, moreover, may be continuous or intermittent with brief clamp release. Liver clamping has two main repercussions: splanchnic and systemic hemodynamic disturbances and visceral ischemia.

Each type of clamping is more or less easy to carry on. Each of them has its advantages and disadvantages.

\section{Clamping of the hepatic pedicle. Pringle maneuver}

Clamping of the hepatic pedicle (the so-called Pringle maneuver) aims at interrupting the arterial and venous inflow to the liver but has no effect on back flow bleeding from branches of the hepatic veins.

\section{Technique}

Adhesions to the gallbladder are freed and the lesser omentum is opened at the level of the pars flacida, taking care to avoid an injury to the right gastric pedicle. A finger or blunt dissector may thereafter be easily passed through the Winslow's foramen and the hepatoduodenal ligament encircled with a tape. Clamping is easily achieved by a vascular clamp that should be grasped until the pulse in the hepatic artery distal to the clamp is stopped.

\footnotetext{
Liver and Portal Hypertension Surgery Unit; ${ }^{2}$ Department of Surgery, ${ }^{3}$ Department of Gastroenterology, University of São Paulo School of Medicine; ${ }^{4}$ Oncology Institute of the Santa Paula Hospital, São Paulo, SP, Brazil.

Address for correspondence: Dr. Eleazar Chaib - Rua Embaú, 206 - ap. 131 - 04039-060 - São Paulo, SP, Brazil. e-mail: cientifico@uol.com.br
} 
Excessive grasping should be avoided as it may otherwise result in arterial or biliary injury. Care should also be taken to avoid injury to lymph nodes of the hepatoduodenal ligament (these may be particularly large in cirrhotic patients or in patients with a long standing cholestasis) as significant bleeding from these lymph nodes may occur once the clamp has been applied.

A careful search for a left hepatic artery originating from the left gastric artery is mandatory to prevent persistent bleeding during parenchyma transection. When a left hepatic artery is present, a simultaneous occlusion of this vessel should be performed.

In patients who have undergone previous abdominal surgery, there may be some dense adhesions between the right lateral and posterior aspects of the hepatoduodenal ligament (in particular the portal vein) and the anterior surface of the inferior vena cava and segment I. These should be freed prior to attempting to control the hepatoduodenal ligament. A safe approach to perform this is to expose the inferior vena cava in its retropancreatic portion by a Kocher maneuver and progress cranialy.

On the left side, one should get into contact with the anterior part of segment I and progress gently to the right by blunt dissection. The anterior aspect of the hepatoduodenal ligament may alternatively be overlaid by adhesions of the duodenum or the greater omentum to segment IV. These also should be divided as clamping may otherwise be ineffective or result in duodenal injury.

Interruption of the hepatic inflow to a normal liver under normothermic condition is safe for up to 60 minutes ${ }^{(12)}$. Clamping of the hepatic pedicle can be applied either in a continuous fashion until the transection is finished or in an intermittent fashion (15 minutes of clamping followed by 5 minutes of unclamping) (Figure 1). Intermittent clamping may increase the total ischemia time especially in the cirrhotic liver ${ }^{(20)}$. The drawback of this intermittent clamping is that the transection plane may bleed when the clamp is released; blood loss may however be efficiently prevented by gently compressing both cut surfaces together.

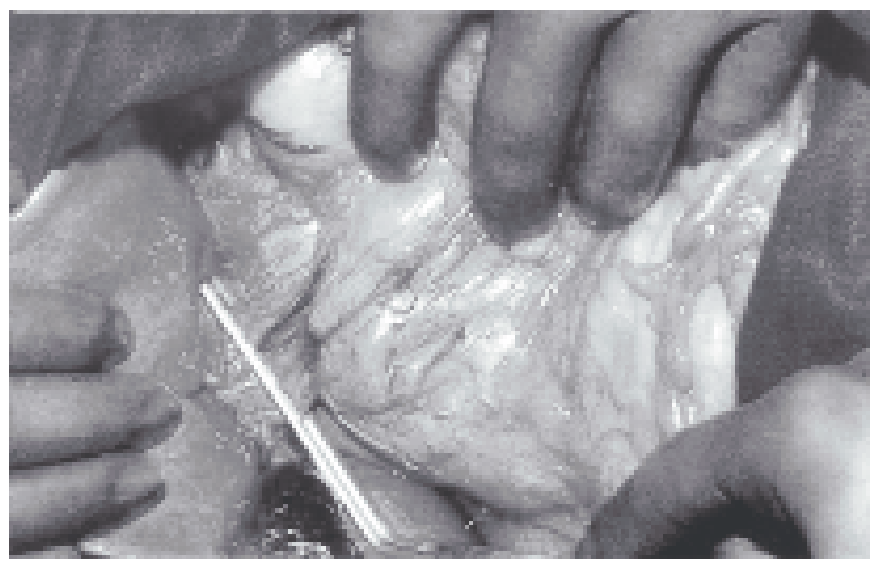

FIGURE 1 - Pringle maneuver a vascular clamp has been applied in the hepatic hilum

\section{Indications}

It is the simplest method, and it can be used safely during one hour ${ }^{(5,8,12)}$. It has almost no systemic hemodynamic repercussion, although some patients with unstable cardiovascular status can present a dangerous arterial pressure decrease, requiring a fluid overload that increases venous pressure, leading to blood loss from intrahepatic veins.

We use it only for fast wedge resections, or segmentectomies located distally to the terminal part of the hepatic veins (in the inferior parts of the liver), in the presence of normal liver parenchyma.

It is also indicated for minor and major hepatic resections provided that the trunk of the major hepatic veins and/or the inferior vena cava are not involved.

Patients with right heart failure, pulmonary artery hypertension or tricuspid valve insufficiency, it may prove impossible to reduce the central venous pressure and hence a total vascular exclusion rather than a simple inflow occlusion should be considered.

Because it is difficult to predict the exact duration of the liver resection, and because we like to progress slowly and have enough time, we generally prefer to use the intermittent clamping.

\section{Intermittent clamping of the hepatic pedicle}

Its main advantage is to have time to do hepatectomy. In a preliminary report, ELIAS et al. ${ }^{(6)}$, concluded that it was useful in cases of difficult or long hepatectomy because it avoids haste. It is well tolerated for more than $120 \mathrm{~min}$, including patients with pathological liver parenchyma. Recently, one team ${ }^{(15)}$ reported one case of isolated complete resection of the caudate lobe, with an intermittent clamping of $195 \mathrm{~min}$ durations, and another the longest ischemic time of 204 min in a cirrhotic patient ${ }^{(20)}$. During declamping periods, blood loss was very small, because liver raw surfaces are gently manually squeezed.

In a randomized experimental study ${ }^{(13)}$ and in a randomized clinical study ${ }^{(17)}$, the liver tolerated intermittent clamping better than continuous clamping. Therefore, intermittent clamping should be recommended for most of the anatomical and non-anatomical hepatectomies, especially when the tumor(s) lies close to the arterial or portal vessels, and when abnormal consistency of the liver parenchyma requires a slow and meticulous operative technique and when there are several large raw surfaces inside the liver. Sometimes the close location of the tumor to the cava or to the terminal part of the hepatic vein, the presence of an impaired liver parenchyma, or an unusual high venous pressure, convince to use an other type of clamping.

In fact, continuous or intermittent Pringle ${ }^{(14)}$ maneuver induces only partial ischemia of the liver and it was clearly proven that hepatic vein «run off» can give hemorrhage, caval blood filling the hepatic venous bed with respiratory movements ${ }^{(2)}$. 


\section{Intermittent vascular exclusion of the liver (IVEL) without vena cava clamping}

\section{Technique}

IVEL consists in successive periods of 20 min of clamping of the hepatic pedicle, and the terminal part of the hepatic veins (without vena cava clamping). Between each period of clamping, respite lasted 5 minutes. During this time, the raw liver surfaces were gently squeezed manually. There was no limitation of time during the IVEL.

Some pitfalls about surgical technique are important:

1. complete dissection of the falciform;

2. right and left coronary ligaments are taken up to the confluence between the suprahepatic vena cava and hepatic veins.

Then, the tongue of smooth tissue covering the vena cava is pelted caudally, allowing exposition of the angle between the right vein and the common trunk. Occasionally, the common trunk is replaced by two (the middle, and the left veins) or three veins (the middle, and two left veins).

On the right side, after a complete right lobe mobilization, the retrohepatic vena cava is exposed and loops are passed around accessory right inferior veins if greater than $5 \mathrm{~mm}$ in diameter. Veins smaller than $5 \mathrm{~mm}$ in diameter are ligated. Looping the terminal part of the right vein is rather easy, and is considered as standard practice.

On the left side, the ligatum venosum (ligament of Arentius) is divided to its junction with the upper part of the segment $I$. The upper parts of the segment I must be tracted anteriorly and to the right with one finger to gently dissect the smooth tissue inserted between its apex and the anterior face of the vena cava. So the junction between the left hepatic vein and the vena cava can be exposed from below. With a large blunt dissector, a slit is gently created under the root of the common venous trunk.

The common trunk is looped, and will be tied later with a tourniquet. Before beginning this maneuver, the suprarenal vena cava has been controlled with a loop, and the possibility to clamp very rapidly the suprahepatic vena cava with a "de Bakey" clamp has been tested. The maximum of loops passed around different hepatic veins, in one patient, was seven: four upper hepatic veins (one right, one central, and two left), two inferior right hepatic veins, and one big inferior vein for segment one.

With this technique, the segment I superior veins are the only veins that are not controlled.

Major advantages of this new technique are: no time limit, and no hemodynamic detrimental effects secondary to caval flow interruption.

When a patient cannot tolerate vena cava clamping, an extracorporeal venous bypass by pump, or IVEL, must be used.

Disadvantages of this technique are: the need of an extensive liver dissection to control its vascular structures (feasible in $90 \%$ of the cases), and its inefficiency in $10 \%$ of patients.

\section{Indications}

Total or partial IVEL is extremely beneficial in the following situations:

1. patients who should have classical vascular exclusion of the liver but cannot tolerate vena cava clamping. By extension we used invariably this technique in all instable cardiovascular status patients;

2. patients with pathological liver parenchyma and high intrahepatic venous pressure;

3. patients who have an abnormal liver parenchyma and for whom conservative surgery leads to an anatomic or nonanatomic resection close to a vein (like a tumor located in the dihedral angle of the terminal parts of two veins);

4. in cases of tumors situated close to a hepatic vein that must be kept, such as a left trisegmentectomy necessitating pelting of the right hepatic vein, and

5. in the unusual cases of tumors infiltrating the major hepatic veins, requiring vein reconstruction to preserve liver function ${ }^{(16,19)}$.

It is frequent to meet an association of these different situations.

\section{Hepatic vascular exclusion with vena cava clamping}

Hepatic vascular exclusion (HVE) combines a total inflow and outflow vascular occlusion of the liver. This procedure completely isolates the liver from the circulation and primarily aims at preventing bleeding and air embolism from injuries to major hepatic veins and/ or the inferior vena cava (IVC).

\section{Technique}

The patient is placed in the supine position over a warming blanket. The approach is through a bilateral subcostal incision and its possible extensions have been previously described ${ }^{(3,10)}$. Mobilization of the liver is mandatory to obtain a good exposure of the retrohepatic and supra hepatic IVC.

The liver is completely mobilized by dividing the falciform, left and right triangular ligaments as well as all adhesions to the liver. The posterior surface of the right lobe is freed from the retroperitoneum overlaying the adrenal gland until the right border of the IVC is exposed.

The IVC is mobilized above and below the liver and encircled (Figures 2, 3). The right adrenal vein should be ligated unless the inferior clamp can be applied above its junction with the IVC. The hepatoduodenal ligament is encircled as described above and a careful search for a left hepatic artery originating from the left gastric artery is made ${ }^{(10)}$

An initial trial of vascular exclusion must be undertaken for up to 5 minutes, after the blood volume has been adequately expanded, to ensure that the procedure will be well tolerated ${ }^{(5)}$. The central venous pressure should be maintained below $12 \mathrm{~cm} \mathrm{H}_{2} \mathrm{O}$ to avoid excessive 


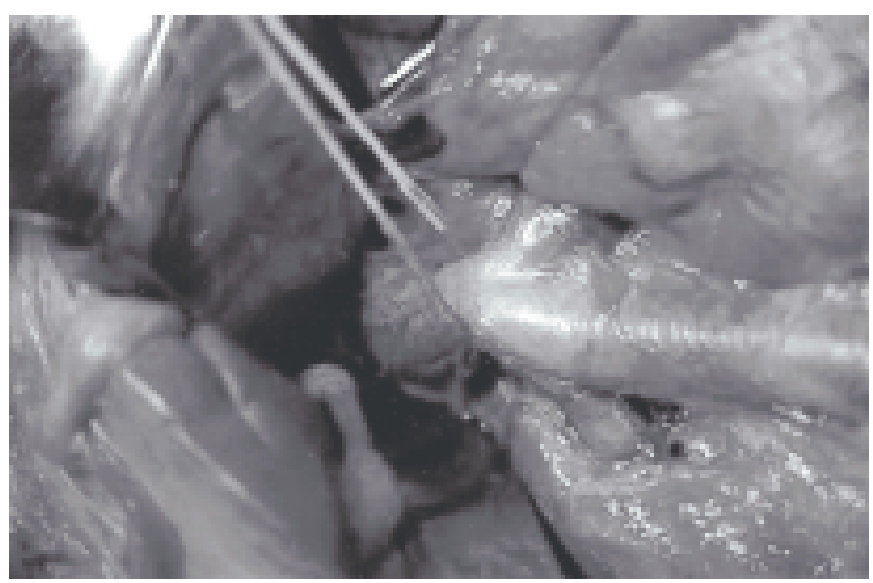

FIGURE 2 - Isolation of the inferior vena cava above renal veins

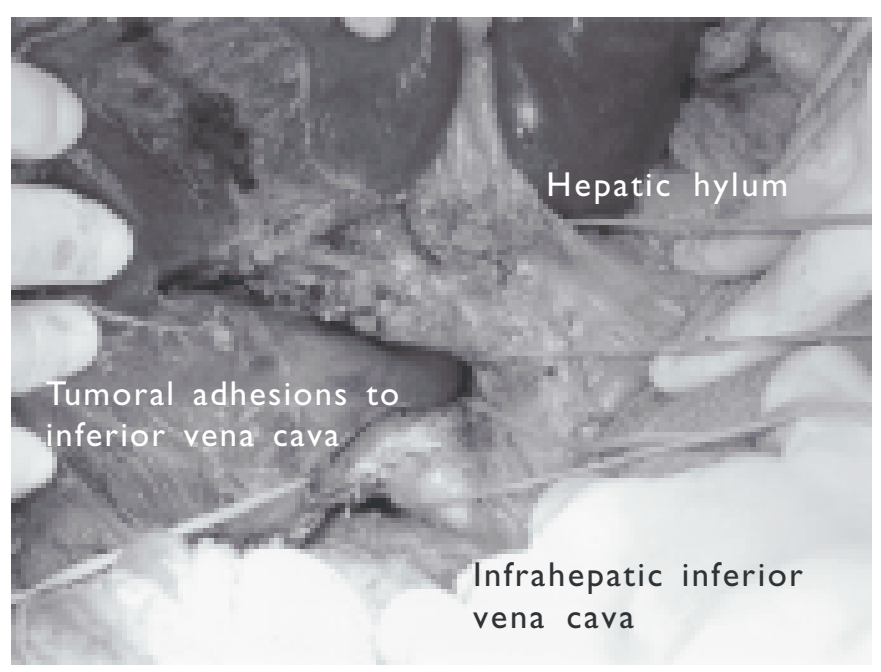

FIGURE 3 - Vascular exclusion of the liver showing both hepatic hilum and infra-hepatic inferior vena cava isolation and suprahepatic inferior vena cava encircled with a tape

backflow bleeding once the clamps are released. A fall in cardiac output exceeding $50 \%$, and/or a decrease in mean arterial blood pressure greater than $30 \%$ (i.e. less than $80 \mathrm{~mm} \mathrm{Hg}$ ), should be considered as contraindications to HVE.

Clamps are applied in the following order:

1. hepatoduodenal ligament;

2. infrahepatic IVC, and

3. suprahepatic IVC.

The positioning of the two caval clamps is most important to control any flow from collateral veins into the excluded segment of IVC which might cause liver congestion, hemodynamic collapse and severe bleeding during liver transection ${ }^{(10)}$. Vascular clamping is not interrupted until the end of liver resection.

Prior to liver resection, a short HVE test of $3 \mathrm{~min}$ is done to assess the hemodynamic tolerance. Vascular overloading $(500 \mathrm{~mL}$ of colloids) is useful before HVE. Central temperature is recorded. Arterial blood gases, $\mathrm{pH}$ and coagulation tests are regularly controlled during and after surgery.

After completing the parenchyma transection and prior to removing the clamps, the infrahepatic clamp can be partially released to flush air that might have been trapped and to check for caval integrity. The clamps are then removed in the reverse order to which they were initially placed.

HVE is well tolerated by a normal liver parenchyma for up to 60 minutes. The spontaneous fall in the temperature of the excluded liver seems itself beneficial to improve tolerance to ischaemia ${ }^{(4)}$. HVE cannot be applied in an intermittent fashion as the caval flow cannot be interrupted and released sequentially.

\section{Indication}

HVE is indicated when major hepatic resections for lesions involving the cavo-hepatic junction are considered or when significant backflow bleeding occurs due to an inability to lower the central venous pressure.

\section{DISCUSSION}

The purpose of vascular clamping during the course of liver resection is to reduce bleeding and subsequent complications. As soon as PRINGLE ${ }^{(18)}$ described the temporary clamping of the whole portal pedicle to obviate the risk of arterial and portal venous bleeding. Obviously, this maneuver offers no protection against the risk of hemorrhage from the IVC or hepatic veins. Bleeding from these veins may be massive and associated with gaseous embolism, generally lethal.

\section{Hemodynamic response}

The classical hemodynamic response to clamping of the hepatic pedicle is a $10 \%$ increase of mean arterial pressure, a $40 \%$ increase of systemic vascular resistance, a 5\% decrease of pulmonary artery pressure and a $10 \%$ decrease of cardiac index. This clamping is usually extremely well tolerated as it does not interrupt the caval flow. No specific anesthetic management is required.

\section{Intermittent or continuous clamping?}

Portal triad clamping is associated with liver ischemia and splanchnic venous stasis. It has been suggested that poor tolerance to PTC in laboratory animals is mainly due to splanchnic venous stasis ${ }^{(13)}$.

To minimize the consequences of ischemia and portal blood stasis, some surgeons suggested to use a new method of repeated intermittent clamping, with a brief reperfusion period ${ }^{(17)}$. 
To confirm the superiority of intermittent over continuous clamping, ISOZAKI et al. ${ }^{(13)}$ compared in rats the tolerance of the liver to ischemia during intermittent or continuous clamping of the hepatic pedicle. Intermittent clamping was tolerated significantly better than continuous clamping, with higher 7-day survival. No additional improvement was produced by shortening the intermittent clamping period from 30 to 15 minutes.

BELGHITI et al. ${ }^{(1)}$, who conducted a randomized clinical study comparing continuous or intermittent PTC, found the latter to be better tolerated than the former, especially in cirrhotic patients. These data support the view that intermittent clamping of the hepatic pedicle is more "physiologic" than continuous clamping.

\section{Technical failure}

Persistent bleeding during parenchyma transection usually results from:

1. an incomplete inflow occlusion and/or

2. a backflow bleeding through the hepatic veins.

Incomplete inflow occlusion is prevented by applying and grasping the clamp adequately and by also occluding a left hepatic artery if this is present. Patients whose hepatic artery has been ligated or who have been treated by arterial embolization may develop hypervascular adhesions around the liver; these should be divided prior to vascular clamping.

The likelihood of backflow bleeding is reduced by maintaining the central venous pressure below 8-10 $\mathrm{cm} \mathrm{H}_{2} \mathrm{O}$. However, the presence of a low central venous pressure regimen increases the risk of air embolism if an injury occurs to the hepatic veins or to the inferior vena cava. This complication can be prevented by avoiding extensive dissection of the hepatic veins and by placing the patients in the Trendelenburg's position.

Should an injury to the major hepatic veins or the inferior vena cava occur, the liver should be replaced immediately in its anatomic position (this will usually temporarily control or reduce the bleeding), the patient placed in the Trendelenburg's position and, if necessary, the ventilation pressure increased before attempting to repair the injury.

HEANEY et al. ${ }^{(9)}$ introduced the concept of hepatic vascular exclusion (HVE) by occluding the portal triad, the IVC below and above the liver and the supraceliac aorta. Their initial experience of HVE was reported in 1973 with a modified technique, i.e. control of the IVC below the diaphragm and omission of aortic clamping ${ }^{(10,12)}$.

Hemodynamic monitoring includes heart rate, radial artery pressure, pulmonary artery pressure and cardiac output through a Swan Ganz catheter.

It is used only by necessity, when the tumor(s) invades the vena cava or is very close to it (with compression and doubt about its invasion), or when the tumor is close to the terminal part of a vein that must be preserved.

This classical vascular exclusion has two disadvantages: its limited duration, and its detrimental hemodynamic effects.

It can be used only for a little more than one hour. In spite of a good pre-loading of the circulation, $18 \%$ of our patients $(18.4 \%$ in Huguet's series) ${ }^{(7)}$ could not support vena cava clamping.

\section{Hemodinamic consequences}

During hepatic vascular exclusion, the cardiac index decreases about $50 \%$, the mean arterial pressure decreases about $15 \%$, the pulmonary capillary wedge pressure decreases about $75 \%$, and the systemic vascular resistance increases about $80 \%{ }^{(5)}$.

Return to normal is observed very rapidly after removal of the clamps. Poor hemodynamic tolerance is most often due to incomplete HVE responsible for back flow into the retrohepatic IVC between the two clamps and blood sequestration in the liver.

Persistent intolerance may require aortic clamping at the supra celiac level, or preferably associated veno venous bypass to decompress both splanchnic and systemic territories.

We have frequently combined intermittent clamping of the pedicle during the first step (anterior approach) of a hepatectomy (with a fluid underloaded patient). In addition, we have overloaded the patient during a declamping period, and used the vascular exclusion of the liver to finish the posterior part of the liver resection (when finishing on the vena cava was problematic).

\section{Metabolic consequences}

Normothermic liver ischemia during HVE may be tolerated without any deleterious consequences for 1 hour and even more if the hepatic parenchyma is normal ${ }^{(11)}$.

Tolerance of cirrhotic livers to ischemia is still controversial. ChildPugh A group - which are the unique acceptable category for surgical resection - may tolerate as well as non-cirrhotic patients, but the morbidity and mortality after liver resection are usually higher independently of the hepatic ischemia.

Hypothermic perfusion of the liver associated with HVE might help to protect impaired livers if prolonged vascular clamping is predictable ${ }^{(4)}$.

\section{CONCLUSION}

The choice of technique to use for clamping during hepatectomy depends on the surgeon's judgment. Dogmatic, or systematic attitude, is prejudiciable for the patient, and liver surgeon must be able to use all kinds of clamping. 
Chaib E, Saad WA, Fujimura I, Saad Jr WA, Gama-Rodrigues J. Principais indicações e técnicas para exclusão vascular do fígado. Arq Gastroenterol 2003;40(2):131-136.

RESUMO - Racional - O clampeamento vascular hepático durante as hepatectomias tem como meta reduzir o sangramento e suas complicações. Objetivo - Mostrar passo a passo as principais técnicas cirúrgicas para exclusão vascular do fígado e suas indicações. Método - São descritas as seguintes técnicas: clampeamento do hilo hepático, manobra de "Pringle"; clampeamento intermitente do pedículo hepático; exclusão vascular intermitente do fígado, sem clampeamento da veia cava inferior e a exclusão vascular hepática com clampeamento da veia cava inferior. Discutem-se, também, as conseqüências hemodinâmicas e metabólicas, bem como as falhas técnicas de cada uma destas manobras. Conclusão - A escolha da técnica de exclusão vascular durante a hepatectomia depende da avaliação do cirurgião. Atitudes dogmáticas e sistemáticas são prejudiciais para o paciente e os cirurgiões de fígado devem estar habituados a usar qualquer uma das manobras.

DESCRITORES - Hepatectomia. Constrição. Circulação hepática. Hemostasia cirúrgica.

\section{REFERENCES}

1. Belghiti J, Noun R, Zante E, Ballet T, Sauvanet A. Portal triad clamping or hepatic vascular exclusion for major liver resection. A controlled study. Ann Surg 1996;224:155-61.

2. Brauer RW. Liver circulation and function. Physiol Rev 1962;43:115-213.

3. Cunningham JD, Fong Y, Shriver C, Melendez J, Marx WL, Blumgart LH. One hundred consecutive hepatic resections. Blood loss, transfusion, and operative technique. Arch Surg 1994;129:1050-6.

4. Delriviere L, Hannoun L. In situ and ex situ in vivo procedures for complex major liver resections requiring prolonged hepatic vascular exclusion in normal and diseased livers. J Am Coll Surg 1995;181:272-6.

5. Delva E, Camus Y, Nordlinger B, Hannoun L; Parc R; Deriaz H; Lienhart A; Huguet C. Vascular occlusions for liver resections. Operative management and tolerance to hepatic ischemia: 142 cases. Ann Surg 1989;209:211-8.

6. Elias D, Desreunnes E, Lasser P. Prolonged intermittent clamping of the portal triad during hepatectomy. Br J Surg 1991;78:42-4.

7. Gavelli A, Jobard J, Huguet C. [Poor haemodynamic tolerance to hepatic vascular exclusion: 9 in 49 patients (in French)]. Lyon Chir 1994;90:367-70.

8. Hannoun L, Borie D, Delva E, Jones D, Vaillant JC, Nordlinger B, Parc R. Liver resection with normothermic ischemia exceeding one hour. Br J Surg 1993;80:1161-5.

9. Heaney JP, Stanton WK, Halbert DS, Seidel J, Vice T. An improved technic for vascular isolation of the liver: experimental study and case reports. Ann Surg 1966;163:237-41.

10. Huguet C, Addario-Chieco P, Gavelli A, Arrigo E, Harb J, Clement RR. Technique of hepatic vascular exclusion for extensive liver resection. Am J Surg $1992 ; 163: 602-5$
11. Huguet C, Gavelli A, Addario-Chieco P, Bona S, Harb J, Joseph JM, Jobard J, Gramaglia M, Lasserre M. Liver ischemia for hepatic resection: where is the limit?. Surgery 1992;111:251-9.

12. Huguet C, Gavelli A, Bona S. Hepatic resection with ischemia of the liver exceeding one hour. J Am Coll Surg 1994;178:454-8

13. Isozaki H, Adam R, Gigou M. Experimental study of the protective effect of intermittent hepatic pedicle clamping in the rat. Br J Surg 1992;79:310-3

14. Kim Y, Ishii T, Aramaki M. The pringle maneuver induces only partial ischemia of the liver. Hepatogastroenterology 1995;42:169-71.

15. Kosugue T, Yamamoto J, Takayama T, Shimada K, Yamasaki S, Makuuchi M, Hasegawa $\mathrm{H}$. An isolated, complete resection of the caudate lobe, including the paracaval portion, for hepatocellular carcinoma. Arch Surg 1994;129:280-4.

16. Nakamura S, Sakaguchi S, Hachiya T, Suzuki S, Nishiyama R, Konno H, Muro $\mathrm{H}$, Baba S. Significance of hepatic vein reconstruction in hepatectomy. Surgery 1993;114:59-64.

17. Pierangeli F, Jagot P, Farges O. Intermittent or continuous hepatic pedicle clamping. A randomized study [abstract]. HPB Surg 1996;9:F099.

18. Pringle JH. Notes on the arrest of hepatic hemorrhage due to trauma. Ann Surg 1908;48:541-9

19. Takayama T, Nakatsuka T, Yamamoto J, Shimada K, Kosuge T, Yamasaki S, Kakazu T, Makuuchi M. Re-reconstruction of a single remnant hepatic vein. $\mathrm{Br}$ J Surg 1996;83:762-3.

20. Wu CC, Hwang CR, Liu TJ, P'eng FK. Effects and limitations of prolonged intermittent ischaemia for hepatic resection of the cirrhotic liver. Br J Surg 1996;83:121-4. 